\title{
Frederick Lanchester and the invention of the air-supported roof
}

\author{
Will McLean \\ University of Westminster, London, UK
}

\begin{abstract}
In 1917 Frederick W. Lanchester (1868-1946) applied for the first UK patent for an airsupported structure, and in 1920 Lanchester registered another patent for an air-supported 'domed' exhibition hall with a proposed diameter of $329 \mathrm{~m}$. Whilst neither of these structures were realised, both designs featured in key architectural publications and can be credited as the antecedents of an emerging technology. Lanchester, an engineer and polymath is best known for his work in automotive engineering, aeronautics and powered flight, and thanks to the recent publication of his archive, an analysis of his calculations and notebooks is now possible. The paper concludes by describing the subsequent development and realisation of air-supported and air-formed structures by engineer Walter Bird (1912-2006) and architect Dante Bini (1932-), and features previously unpublished archive diagrams and notes, documenting the invention of a remarkable new type of structural enclosure entirely supported by differential air pressure.
\end{abstract}

Keywords: Frederick W. Lanchester (1868-1946), Temporary Structures (UK, US, Japan), AirSupported Structure (Inflatable), Mamoru Kawaguchi (1932-), Graham Stevens (1944-)

\section{FREDERICK LANCHESTER}

Frederick Lanchester (1868-1946) was an engineer and inventor and can be justifiably described as a polymath of whose interests and expertise ranged from automotive, aeronautical, nautical, sound and music (Fig. 1). In the field of aeronautics, but in particular the automotive industry Lanchester can be seen as a key and pioneering figure in the development of the modern motor car and associated automotive technologies. During his professional life, Lanchester applied for in excess of 400 patents, 236 of which were successfully granted.

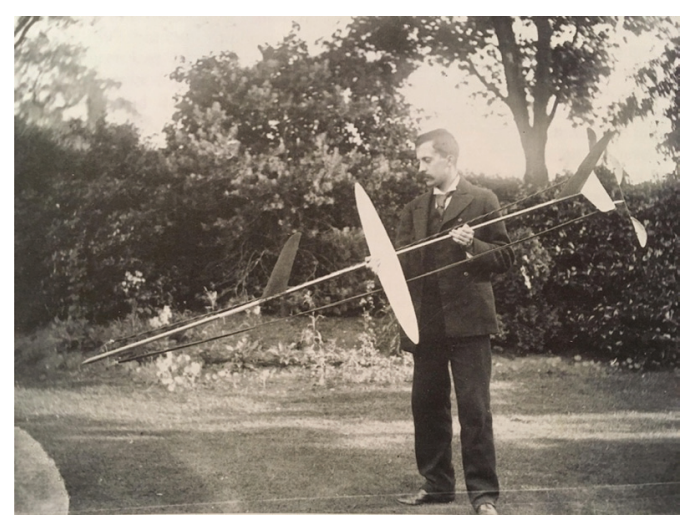

Figure 1. Frederick Lanchester with one of his model gliders, 1894. LAN/7/123. Lanchester Interactive Archive.
"One of his earliest achievements, and one which appealed to the imagination of all, was the first British four-wheeled petrol car, a machine capable of maintaining twelve miles per hour and driven by a six h.p. single cylinder air-cooled engine, which he constructed as far back as 1896." (Lanchester $1938,99)$. In key texts about the history and development of what are variously described pneumatic, inflatable or air structures, Lanchester is widely credited as the originator of the relatively nascent form of construction (Stevens Curl et al. 2016) and in Air Structures: A Survey (Price et al. 1971), two of Lanchester's patents pertaining to air-supported structures were republished as appendices including the first UK patent for an airsupported structure, for "Field Hospitals, Depots and like purposes". Lanchester's works and interests were wide-ranging and have subsequently been expertly recorded in three volumes of reference The Lanchester Legacy published in partnership with Coventry University. The first two volumes primarily cover his automotive works (Clark 1995) (Clark 2016), whilst volume three records some of Lanchester's other works and research with contributions from physicists, engineers, aerospace and operational research specialists (Fletcher 1996).

In 2017, Coventry University Library in collaboration with Disruptive Media Learning Lab launched the Lanchester Interactive Archive (LIA), alongside an interactive exhibition housed in the Lanchester Library - Coventry University was formerly known as the Lanchester Polytechnic until 


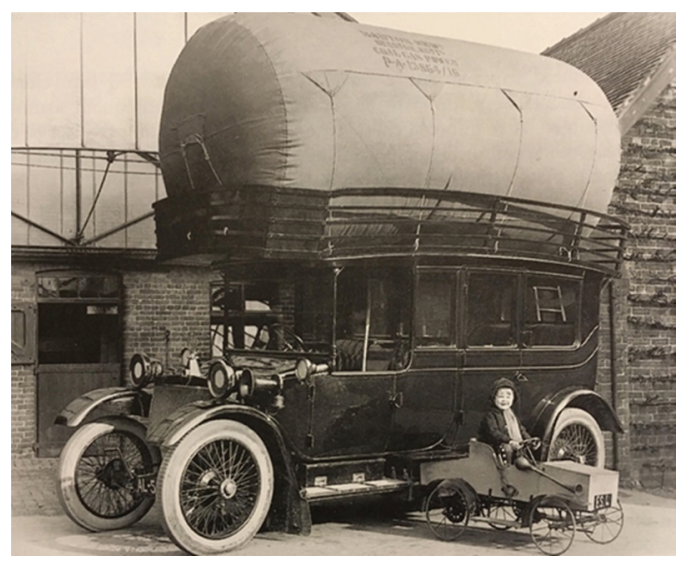

Figure 2. A Lanchester38 h.p. limousine converted to coal-gas in advance of World War One pictured with Lanchester's niece, 1912.Lanchester Interactive Archive.

1987. It is only through the dedication of enthusiasts and independent scholars such as Chris Clark, that such a resource as LIA was established. LIA provides online access for high quality scans of Lanchester's notebooks, sketchbook, patents and a photographic history of his automotive works.

The work of a polymath like Lanchester is necessarily diverse and broadly themed, but what remained unclear was the impetus for his works with air-supported structures. The biographical and familial links were instructive with Frederick the son and one of eight children by architect father Henry Jones Lanchester (1834-1914) and teacher Octavia Ward (1834-1916). Frederick would go on to work with brothers George and Francis in the development of the Lanchester car company. Fredericks eldest brother Henry followed his father into the architectural profession and was responsible for a number of public buildings that included Cardiff Civic Hall and Law Courts, Central Hall Westminster and Hull School of Art. Henry was listed as a member of the Architectural Association and for a time Fredericks address was listed as 41 Bedford Square in London's Bloomsbury. Bedford Square has been home to the Architectural Association School of Architecture since it moved there in 1917. Other than the well documented working relationship of brothers and "un-holy trinity" (Fletcher 1996, 4) of Frederick, George and Frank it was unclear to what extent Frederick Lanchester had worked with his architect brother Henry, except for a commission for his own house. Frederick has commissioned his eldest brother to design him a house in Mosely, Birmingham, but "unfortunately Fred did not like the design, so set about making one himself" (Fletcher 1996, 13). Both Henry Vaughan
(Fredericks brother) and his father Henry Jones were well-regarded figures in the architectural profession and his father was involved in local government good works such as sanitary committees after the cholera outbreak of 1865-6 (Fletcher 1996, 23). In 1918 Frederick Lanchester applied for and obtained a patent (Lanchester 1918) for Construction of Tent and Field Hospitals, Depots and Like Purposes. Frederick successfully registered three patents in 1918; the other two Clutch and Change Gear Mechanism more especially applicable to Motor Vehicles and Lubrication of High Speed Reciprocating Engines. So, whilst the field hospital invention might seem at odds with his automotive related innovations, the timing, at the end of World War One and the imperative for temporary accommodation makes more sense.

Around 1918 Lanchester had moved to his London home at 41 Bedford Square, which he had previously bought because of his war-time works which included "...six government committees set up to advise and determine policy on aeronautics in the United Kingdom" (Clark 1995, 161). In 1920 Lanchester filed another patent for his second pneumatic structure, Construction and Roofing of Buildings for Exhibitions and Like Purposes (Lanchester 1920) (Figs. 3-5). In that year Lanchester had applied for eight patents,
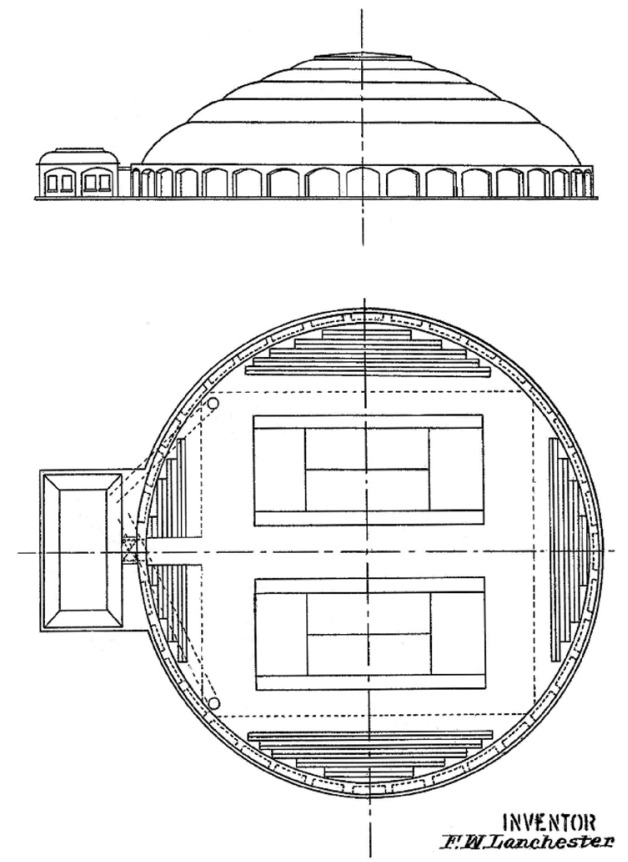

Figure 3. Elevation and plan of the $50 \mathrm{~m}$ diameter dome to enclose two tennis courts, excerpt from Patent 145193,1920 
which were subsequently granted. His second patent pertaining to building was preceded by Gear Changing Mechanisms for Mechanically Propelled Vehicles and followed by Actions of Pianofortes. Both of Lanchester's building patents employed the use of pressurised air as the principle means of support and can be described as the first documented examples of air-supported structures (McLean et al 2015).

This type of construction is also referred to as a super-pressure building (Silver et al 2013) and in the most generic sense a pneumatic or inflatable structure. An air-supported structure requires a small and continuous pressure differential from inside to outside of the structure in order to hold the building fabric aloft. To maintain the internal air-pressure an air-lock needs to be employed, which might consist of two sets of doors and a lobby, or revolving doors. In both his patents, Lanchester carefully describes the principles by which an air-supported structure is supported and fabricated by means of rope and canvas including details of fixings and material construction (Fig. 4). Sketches in his notebooks (Fig. 6), include engineering calculations as well as specifications for the canvas skin and rope cabling, fastening and anchoring designs.
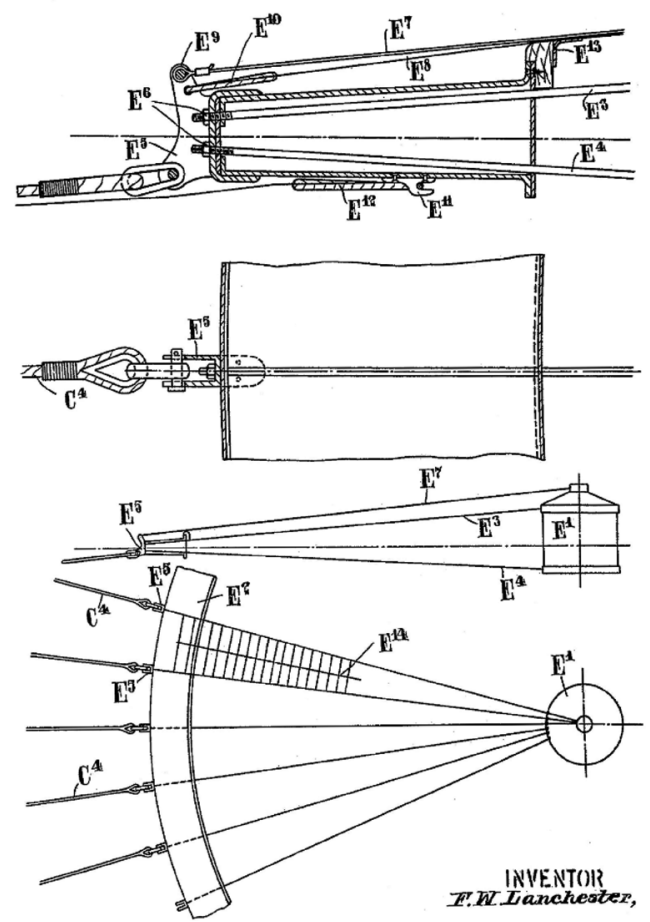

Figure 4. Details showing how the translucent lantern might be attached to the canvas skin, excerpt from Patent 145193, 1920.

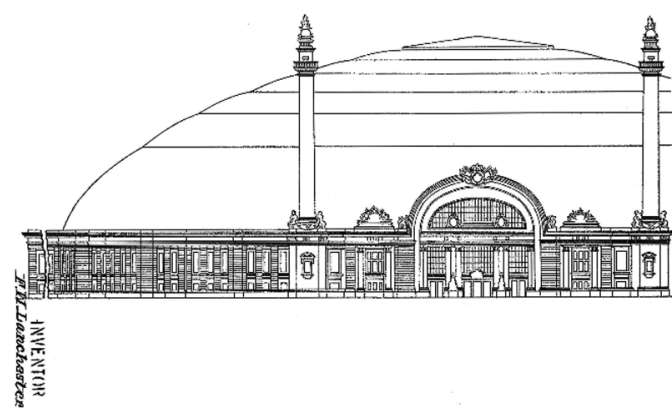

Figure 5. Elevation of $150 \mathrm{~m}$ diameter dome in collaboration with architect brother Henry, excerpt from Patent 145193, 1920.

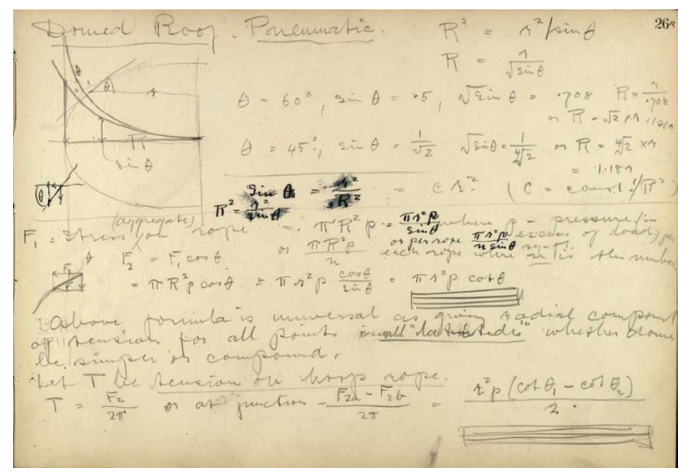

Figure 6. Page from Lanchester's sketch book showing calculations for domed pneumatic roof, sketch book no. 3, page 26r Reference number LAN/4/3/43, 1914. Lanchester Interactive Archive.

\section{SPAN: THE SPANNING OF DISTANCE}

The most comprehensive and most comprehensible description of Lanchester's designs for air-supported structures is to be found in his published lecture SPAN (Lanchester 1938). The lecture was the second annual lecture given to the Manchester Association of Engineers on Wednesday 9th November 1938. Lanchester takes as his central theme and Part I of the talk The Spanning of Distance. Lanchester discusses the comparative benefits of a suspension bridge versus a cantilever and delivers a kind of mild take down of the Forth rail bridge, at once acknowledging its status as an extremely fine example of structural engineering, but one in which only special circumstances could justify (Lanchester 1938, 66). Lanchester discusses the spanning distance of bridges, but also their quantitative use of materials with the suspension bridge winning every time. Interestingly and to conclude the first part of his talk Lanchester makes the point that all bridges are not equal 
when attempting a like for like comparison and whilst Benjamin Baker's Forth Rail Bridge (Silver et al 2013,120-121) is structurally self-contained the arch of Sydney Harbour Bridge (1932) relies as much on "mother earth" for its abutments as it does on its engineering. Lanchester concludes "... the same may be said of the suspension bridge, the cables have ultimately to be anchored somewhere, and if it were not for the good earth, a compression strut would be necessary to run the whole length of the cable" (Lanchester 1938, 67). In Part II of his talk Lanchester discusses The Spanning of Area, but discounts the great spanning roofs of exhibition buildings and railway terminae "... structurally as a mere aggregation of bridges" and he concentrates on the dome which he regards "... as the greatest architectural invention of all time." The Pantheon is of particular interest including the oculus whilst the catenary analysis of the structural success of the dome of St Pauls is broadly dismissed "...it seems to have been tacitly assumed without proof that the solution to a problem in two dimensions is equally the solution to an analogous problem in three dimension." (Lanchester $1938,80)$. In the final and third part of his lecture Lanchester introduces the Air-Borne Span. He explains that some years before the War of 1914 an idea came to him as an 'inventors dream', which he subsequently forgot all about. During the war the need for temporary accommodation became a pressing issue and the idea returned and he planned a model for what he describes as an inflated roof and he also explained the usefulness of a physical model for the client unversed in engineering or reading a drawing. In Figure 2, perhaps we have an unintended model of the inflated structure. The War ended and having failed to complete a model the idea went into what Lanchester described as "cold storage". Two years later and working in collaboration with his architect brother Henry the idea was revived as a design for a large exhibition building. The new proposal outlined in a new patent (Lanchester 1920) included a masonry or concrete surround intended to house smaller exhibits and back of house as well as ingeniously acting as an air lock and anchorage system for the canvas fabric roof restrained with a radial array of ropes. Lanchester was not happy with the naturally inflated form of the roof, which he proposed to control with horizontal circumferential loops to create a large diameter circular profile. Lanchester explained that every time his proposals for such a structure were discussed they evinced a series of stock objections, which he tackles headon with answers to questions of; heating and ventilation, lighting, entry and exit, and fire risk. In regards to lighting, it was proposed to utilise the natural translucency of fabric with any additional day-lighting requirement made possible through the "...use of a (more translucent) central skylight (lantern) crowning the dome" (Lanchester 1938, 88 ), and 'port-hole' type glazed opening puncturing the skin. In answering questions regarding heating and ventilation Lanchester proposes an internal pressure of $0.1 \mathrm{lb}$./sq. in. $(680 \mathrm{~Pa})$ to maintain the structure of a dome of $50 \mathrm{~m}$ diameter.

\section{"The present invention has for its object to provide a means of constructing and erecting a tent of large size without the use of poles or supports of any kind." F. W. Lanchester, 1917}

In a contemporary comparison, Yutaka Murata and Mamoru Kawaguchi's 'Air-Supported' Orchid Conference pavilions in Kanagawa, Japan erected in 1987 used an air pressure of approximately $300 \mathrm{~Pa}$ in normal conditions, which was increased to approximately $700 \mathrm{~Pa}$ to resist strong winds or snow loads (Kawaguchi, 2009). Bearing in mind the relative lightness of contemporary polymer membranes and modern cabling, Lanchester's approximations are remarkably accurate. Again, Lanchester's prescience is demonstrated in his accurate assessment of the future uses of such structures "In general, the investments that pay best these days are concerned with entertainment and amusement, and it is in this direction that I see the most promising opening for the new form of construction - the pneumatic or inflated roof." (Lanchester 1938, 92). In Figure 3, Lanchester fits two tennis courts within a $50 \mathrm{~m}$ diameter dome, and the air-supported tennis court remains one of the most common uses for this type of structure.

\section{CONCLUSIONS}

Eight years after Frederick Lanchester delivered his SPAN lecture in Manchester, Walter Bird (1912-2006) directed the design and construction of the world's first air-supported radome at Cornell Aeronautical Laboratory in Buffalo, New York (1946) Figure 7. Walter Bird was trained as an aeronautical engineer, graduating from MIT in 1934. Several hundred of these radomes were subsequently built to protect radar antennas from extreme climate. In 1956 he established Birdair Structures, to commercialise his inventions such as pneumatic 'bubble' enclosures for tennis court and swimming pools, which attracted much media attention. Birdair subsequently produced large-scale pneumatic structures (notably with architect Victor Lundy) and led this field through developments of materials and fabrication techniques. 


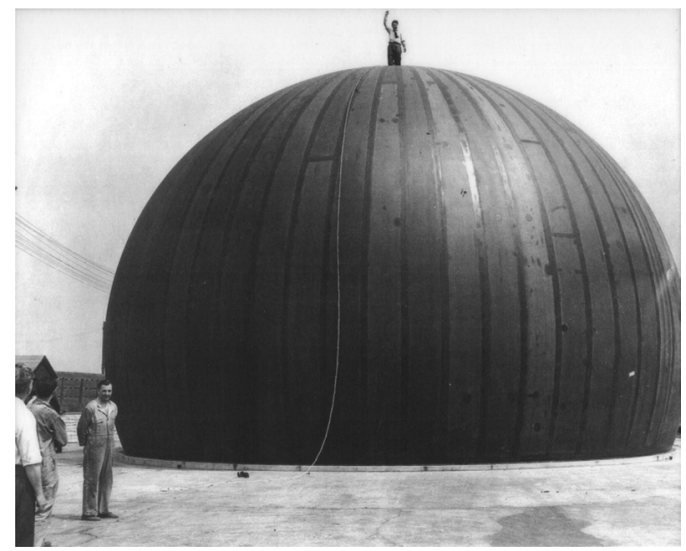

Figure 7. Walter Bird stands atop his inflatable 'Radome' on the Cornell Aeronautical Laboratory grounds, Buffalo, New York, 1946. Birdair Inc.
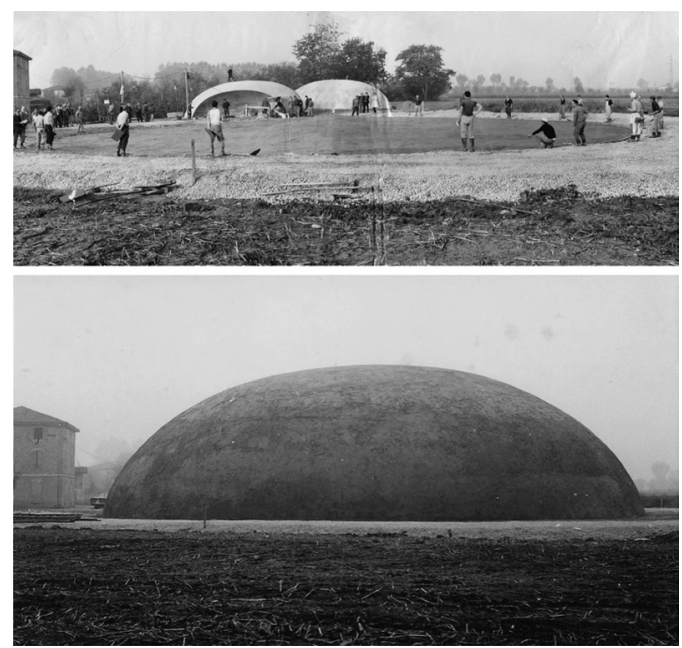

Figure 8. Pictures showing the 'inflation' of the first $30 \mathrm{~m}$ diameter Binishell dome by Dante Bini. Castelfranco Emilia, Italy, 1968. Dante Bini Archive.

In 1967 the University of Stuttgart held the $1 s t$ International Colloquium on Pneumatic Structures (1967). The colloquium, hosted by Frei Otto welcomed the leaders of this rapidly evolving technological art, which included Walter Bird, Victor Lundy, Heinz Isler, Dante Bini, Nikolaus Laing and Cedric Price. Walter Bird presented an overview of the field entitled The Development of Pneumatic Structures, Past Present and Future (Bird et al. 1967).

"The air structure is the most efficient structural form available to date ... no other type of structure has the potential of providing free-span coverage for so large an area ... as the air structure is constructed of light weight, flexible materials, it can be made easily portable and lends itself readily to the design of demountable or removable structures."

Walter Bird, 1967

In a note in the Appendix of his published lecture Lanchester explained that since the delivery of his lecture he had been asked the question, "What about the expense of erecting such a dome as that proposed; will not the cost in centering and labour be prohibitive?" Lanchester responded "The answer is, of course, that it would be erected just as a balloon is erected, by the act of inflation!" And so it was with the Italian architect Dante Bini (1932 -) who became interested in the technology of thin shell concrete domes and was convinced that there must be other ways of forming these doubly curved shell structures. The relative strength of a pneumatic air-supported tennis dome (covered in and supporting a thick layer of snow) gave Bini an idea and in 1965, Bini successfully constructed a $12 \mathrm{~m}$ diameter, $6 \mathrm{~m}$ high hemispherical concrete shell structure (a Binishell) in 3 hours lifting wet concrete using his patented pneumatic formwork. More than 1,500 Binishells were constructed throughout the world between 1970 and 1990 with diameters of between 12 and $36 \mathrm{~m}$ and with a varying elliptical section. Binishells have been fabricated as houses, schools, sports facilities and as industrial storage units (Bini, 2014) (Fig. 8). And whilst Lanchester did not discuss the pneumatic structure as formwork, the technology is identical.

Since the publication of Lanchester's two patents for air-supported structures in 1918 and 1920 the history and development of the inflated building has been uneven and stop-start. With the development of new materials adopted within architecture such as ETFE: Design and Technology (LeCuyer, 2008) there has been renewed interest in this field of air as a structural material to create huge columnless spans and environments, but is seemed to take an eclectic genius like Frederick Lanchester to see the potential in what is still viewed as a highly specialised construction technology. In Appendix II of SPAN Lanchester considers the "maximum or limiting span for an air-borne dome" and concludes "There would seem to be no doubt however, that one mile or even two miles would not be out of reach, if the demand for such a monstrous thing were to arise" (Lanchester, 1938, 94-95).

\section{ACKNOWLEDGEMENTS}

I would like to thank Chris Clark, author, editor and co-publisher of the Lanchester Legacies and 
Gary Collins, archivist at the Frederick Lanchester Library, Coventry University.

\section{REFERENCES}

Bini, Dante. 2014. Building with Air. London: Bibliotheque McLean.

Clark, C.S. 1995. The Lanchester Legacy, A Trilogy of Lanchester Works: Volume One - 1895 to 1931. Coventry: Coventry University.

Clark, C.S. 2016. The Lanchester Legacy, A Series of Lanchester Works: Volume Two 1936 to 1956. Coventry: Lanchester Legacy Ltd.

Feder, D. ed. 1967. Proceedings of the 1st International Colloquium on Pneumatic Structures. University of Stuttgart: International Association for Shell Structures.

Fletcher, John. 1996. The Lanchester Legacy, A Trilogy of Lanchester Works: Volume Three - A Celebration of Genius. Coventry: Coventry University.

Kawaguchi, Mamoru. 2009. Mamoru Kawaguchi: Enginyer d'estructures. Valencia: Universitat Politècnica de València.

Lanchester Interactive Archive. 2017. "Lanchester Archive Catalogue." Last accessed on November 1, 2017. http:// catalogue.lanchesterinteractive.org/
Lanchester, F.W. 1938. Second Annual Lecture on SPAN. Manchester: Butterly and Wood.

Lanchester, Frederick. Construction of Tent and Field Hospitals, Depots and Like Purposes. Patent 119339, 1918.

Lanchester, Frederick. Improvements in the Construction and Roofing of Buildings for Exhibitions and Like Purposes. Patent 145193, 1920.

Lanchester Interactive Archive. 2018. "Lanchester Archive Catalogue." Accessed February 15th, 2018. http://catalogue.lanchesterinteractive.org

LeCuyer, Annette. 2008. ETFE: Design and Technology. Zurich: Birkhäuser

McLean, Will and Pete Silver. 2015. Air Structures. London: Laurence King Publishing.

Price, Cedric, Frank Newby and Robert Suan. 1971. Air structures: a survey commissioned by the Ministry of Public Building and Works. London: H.M.S.O.

Silver, Pete and Will McLean. 2013. Introduction to Architectural Technology. London: Laurence King Publishing.

Silver, Pete, Will McLean, and Peter Evans. 2013. Structural Engineering for Architects: A Handbook. London: Laurence King Publishing.

Stevens Curl, James and Susan Wilson. 2016. The Oxford Dictionary of Architecture. Oxford: Oxford University Press 